\title{
UMA EXPERIÊNCIA NA ESCOLA SOBRE GÊNERO E SEXUALIDADES
}

\author{
Virginia Georg Schindhelm ${ }^{1}$ \\ (Universidade Federal Fluminense) \\ Jonas Alves da Silva Junior ${ }^{2}$ \\ (Universidade Federal Rural do Rio de Janeiro)
}

\begin{abstract}
Resumo: Este trabalho relata uma experiência vivenciada em um curso de Pedagogia e o desconhecimento de alunos para lidar com um colega trajado com roupas e adereços femininos. Refletimos sobre modos de ser/estar no mundo como produções subjetivas e relacionais, manifestadas por inúmeras formas de apresentar-se como homem ou mulher e que se configuram como processos minuciosos, sutis e sempre inacabados de construções pessoais e culturais. O objetivo é problematizar a condição de crianças e jovens em experiências escolares, a partir de questões sobre diversidade cultural e diferença, estereótipos, preconceitos, discriminação e desigualdade. Buscase aprofundar e questionar as concepções e as práticas educativas com sujeitos brasileiros na perspectiva de gênero e sexualidades para a construção de pedagogias que não transformem diferenças em desigualdades. Vivenciar as diferentes sexualidades na escola implica reconhecer as múltiplas formas de experimentar prazeres e desejos, de dar e receber afetos, de amar e ser amado que são ensaiadas e ensinadas nas culturas. Essa variedade foge de controles e de normas, por isso descontrói verdades e padrões. Nosso compromisso docente envolve a construção de conhecimentos e processos sensíveis para desestabilizar padrões normalizadores que funcionam como forças em campos problemáticos como o de gênero e das sexualidades na escola.
\end{abstract}

Palavras-chave: Gênero; sexualidades; escola; diferenças; normatividades.

\section{AN EXPERIENCE AT SCHOOL ON GENDER AND SEXUALITIES}

\begin{abstract}
This work reports an experience in a Pedagogy course and the students' anguish and ignorance in dealing with a colleague dressed in feminine clothes. We reflect on being in the world as subjective and relational productions manifested by the innumerable ways of presenting oneself as a man or a woman which are configured as precise, subtle and unfinished processes of personal and cultural constructions. The objective is to question the children and teenagers' conditions in school experiences, from issues involving cultural diversity and difference, stereotypes, prejudices, discrimination and inequality. Living different sexualities at school involves recognizing multiple ways of experiencing pleasures, desires, of giving and receiving affection, of loving and being loved which are taught in cultures. This variety escapes controls and standards, thus it disregards truths and patterns. As teachers, we are involved in building knowledge and sensitive processes to unbalance prescriptive patterns that function as forces in problem areas such as gender and sexuality at school.
\end{abstract}

Keywords: Gender; sexualities; school; differences; regulations.

1 Doutora em Educação pela Universidade Federal Fluminense; professora adjunta na UFF/INFES campus Santo Antônio de Pádua. Email: psicovir@terra.com.br.

${ }^{2}$ Doutor em Educação pela Universidade de São Paulo; professor adjunto na UFRRJ campus Nova Iguaçu.

Email: jonasjr@usp.br 


\section{Introdução}

Num princípio de semestre como professora de uma disciplina obrigatória num curso de formação de professores recebi uma turma que acabara de ingressar na graduação. Era tudo novidade: a universidade, a professora, alunos que ainda não se conheciam, a disciplina. Nos primeiros momentos os alunos chegaram desconfiados, sentaram nas últimas cadeiras da sala e, na medida em que estas foram sendo ocupadas, outras mais próximas da professora foram sendo ocupadas. No grupo dos últimos alunos que entraram na sala estava um garoto que chamou muita atenção de todos que já estavam na sala porque usava brincos enormes, uma saia comprida estampada, uma sandália colorida e uma camiseta também colorida que modelava seu corpo esguio. Como de praxe, numa turma nova, costumo me apresentar ressaltando rapidamente minha vida acadêmica e meus focos de pesquisa: gênero e sexualidades.

Pedi que os alunos se apresentassem rapidamente, pois a turma era bem grande, privilegiando o nome e o interesse de cada um para escolher esse curso de formação de educadores.

$\mathrm{Na}$ vez do garoto em destaque, ele levantou-se, apresentou-se e deixou a turma desconfortável, na medida em que sua aparência não era condizente com o padrão masculino tão comumente esperado num cenário escolar.

Ao final da aula, alguns alunos me procuraram no corredor buscando orientações sobre como deveriam tratar e lidar com esse colega que instigava nos outros uma nova forma de interação: "não sei como chamar/tratar"; "não sei o que fazer com aquilo" pronunciavam os jovens na expectativa de uma orientação minha.

Percebendo a angústia desse grupo minha orientação foi bem simples e rápida: "perguntem diretamente ao colega como ele gostaria de ser chamado e o respeitem nessa condição; ele é um sujeito e não um aquilo".

Essa experiência nunca saiu de minha memória, todavia ainda me traz reflexões acerca de padrões de comportamento, de transgressões e de apresentações pessoais que costumam servir como provocações para desconstruirmos paradigmas e padrões sociais impostos ainda tão enraizados nas nossas construções pessoais e culturais sobre o certo e o errado, sobre o bom e o ruim, sobre o decente e o indecente, sobre o moral e o imoral, dentre tantas outras dicotomias que nos aprisionam com preconceitos, valores e discriminações.

O objetivo de resgatar essa experiência por meio de uma narrativa é problematizar a condição de crianças e jovens nas suas experiências em instituições escolares, a partir de questões que envolvem diversidade cultural e diferença, estereótipos, preconceitos, discriminação e desigualdade, que consideramos concepções que fornecem instrumentos analíticos para abordar as complexas relações de 
gênero no processo escolar.

Este texto busca contribuir para a reflexão no campo de gênero e das sexualidades, alertando para a questão da diversidade que crianças e jovens brasileiros nos apresentam nas instituições de educação desde a Educação Infantil até a Universidade. O grande desafio é dar visibilidade a um sujeito que difere de um indivíduo homogeneizado e até mesmo universal. Nossa proposta é ainda aprofundar e questionar as concepções e as práticas educativas com sujeitos brasileiros na perspectiva de gênero para a construção de pedagogias que não transformem diferenças em desigualdades.

\section{Sobre uma narrativa de experiência na escola}

Para pensarmos acerca da referida experiência, destacamos algumas questões que nos ajudaram a organizar nossas reflexões.

A primeira delas refere-se ao próprio conceito de experiência, que nos remete a Benjamin (1989) quando o autor postula uma distinção entre experiência e vivência. A vivência (Erlebnis) poderia ser entendida como uma ação/reação que se esgota no momento de sua realização, por isso finita, enquanto experiência (Erfahrung) refere-se ao vivido que é pensado, narrado, uma ação que é contada a um outro, compartilhada, portanto, coletiva e infinita, com um caráter histórico, de permanência, de ir além do tempo vivido. Assim, revelar uma experiência significativa representa mais que a ressignificação do já vivido, mas a experiência do passado marcada e inserida pela perspectiva da atualidade. A partir desses conceitos o autor ressalta a predominância da vivência imediata e o declínio da experiência autêntica, baseada na memória de uma tradição cultural e histórica, no mundo moderno.

Diante disso, narrar uma experiência implica em rememorar cenas que possibilitam conhecer uma história coletiva trançada pelos fios das histórias de cada um (BENJAMIN, 1993). Toda experiência implica em transformar e, por isso, deixa rastros.

Nas suas teses, Benjamin (1987, p. 223) menciona o cronista como um personagem central na modernidade, que narra grandes e pequenos acontecimentos, sem deixar de mencionar que "nada do que aconteceu pode ser considerado perdido na história”. Por isso, como o cronista, narramos uma história por meio de uma reminiscência. E, nesse espaço de intercâmbio de experiências, narramos para o outro algo que nos aconteceu e com o leitor criamos laços quando podemos falar, ouvir e partilhar experiências vividas. Nessa relação entre narrador e ouvinte criamos laços afetivos, promovemos encontros e diálogos.

Nesse sentido, a experiência narrada nesse artigo busca resgatar modos de ser e de estar no mundo, construções subjetivas e relacionais, que se manifestam por gestos, comportamentos e formas de apresentar-se dentre tantas outras maneiras de fazer de alguém um homem ou uma mulher e que requer investimentos continuados nos processos minuciosos, sutis e sempre inacabados que acontecem no âmbito da cultura (LOURO, 2008a). 
A fala angustiada dos jovens mostrou-se como uma história coletiva constituída por normatividades, por referências e por marcas e padrões do que se entende por masculinidades e feminilidades. Por outro lado, o jovem demonstrou uma construção histórica singular que se afastou do padrão e buscou um desvio tornando-se excêntrico. Entendemos por excêntrico aquele que está fora do centro/interior de uma cultura ou ainda que tem um centro diferente e, por isso, é visto como extravagante e esquisito. (LOURO, 2010).

O conceito de centro poderia ser vinculado a uma noção de universalidade, de unidade e de estabilidade, enquanto o diferente poderia ocupar a posição do exótico, do alternativo, do acessório. Nesse sentido, podemos compreender o questionamento dos jovens sobre como lidar "com aquilo", com o estranho, com o exótico ou mesmo com algo que nem sei nomear. Essa seria nossa segunda questão e, mais uma vez, Benjamin (1993, p. 223) nos leva a refletir quando pronuncia "não existem, nas vozes que escutamos, ecos de vozes que emudeceram?” Teria a expressão aquilo o significado de algo inusitado, desconhecido, ou mesmo algo bizarro para formular um sentido para a inesperada aparência do novo colega? Seria ainda uma expressão para desqualificar ou mesmo inferiorizar o sujeito diferente? Lembramos que falar de igualdade e diferença diz respeito a uma rede infinita de conhecimentos e saberes, experiências e vivências tanto coletivas como individuais. Estamos preparados para lidar no cotidiano escolar com o inusitado e com o diferente? Nossa experiência mostrou a angústia nas vozes que falaram e que buscavam significados para o não dito ou, até mesmo, intolerável pensar na convivência com alguém que não corresponde ao modo de ser, de vestir e talvez até pensar de um ser sujeito/homem considerado como normal.

A terceira questão remete à tendência que temos para normatizar e para estereotipar corpos e comportamentos de sujeitos sociais a partir de referências ou mesmo centros baseados em culturas que foram construídas por concepções preconceituosas e discriminatórias para as práticas culturais com marcas da particularidade, da diversidade e da instabilidade. Nesse sentido, vemo-nos diante da identificação das diferenças de gênero ou de sexualidades, percebidas como marcas que pré-existem nos corpos dos sujeitos e que sevem para classificá-los como normais/excêntricos; hetero/homossexuais, dentre outras.

Frente a essas reflexões somos levados a buscar concepções que possam orientar nosso discurso acerca de gênero, sexualidades e diversidades.

\section{Entendendo sobre gênero, sexualidades e diversidades}

Palavras como gênero e sexualidades costumam ser entendidos como sinônimos e confundemse também com sexo. De acordo com o sociólogo inglês Jeffrey Weeks (2001, p. 42) a palavra sexo é conhecida pelo seu sentido biológico, natural, na medida em que descreve as distinções anatômicas 
básicas, internas e externas dadas ao nascimento para o corpo de machos e fêmeas. Ressalta, entretanto, que os significados associados a essas diferenças são históricos, sociais e culturais.

O gênero masculino/feminino pertence ao campo de discussão das representações, dos símbolos e das características social e historicamente atribuídas às diferenças anatômicas, o que significa afirmarmos que sexo e gênero formam um sistema integrado de uma pessoa. O gênero inclui o sexo biológico e engloba as construções sobre o masculino e o feminino, que são produzidas em instâncias socioculturais e históricas de um sujeito.

Weeks (2011) afirma também que o gênero se mostra como uma variável histórica e cultural, potencialmente instável, o que significa uma diversidade nos modos como as sociedades organizam as diferenças sexuais. Sendo assim, longe de ser uma base estável e eterna para a organização da vida social, as relações entre homens e mulheres está sempre sofrendo influências por todo o tempo ao longo da história de instituições, crenças, ideologias e práticas sociais. Nesse sentido, o autor complementa que a construção de gênero pode parecer imutável, mas é objeto de constante fluxo de mudanças nos desejos e nas práticas sociais e pessoais.

De acordo com Connell (1995) gênero é uma estrutura ampla e complexa que mantém uma relação íntima com o campo das sexualidades, na medida em que esta remete a uma dimensão humana singular que envolve as palavras, as imagens, o corpo e as fantasias em processos profundamente culturais e plurais (LOURO, 2001). Na verdade, sexualidades e gênero são categorias com um forte e profundo vínculo inter-relacional, na medida em que são construções histórico-culturais estreitamente ligadas na constituição das subjetividades e, por isso, instáveis e passíveis de transformações.

Sendo assim podemos afirmar que gênero e sexualidades são conceitos amplos com diversos significados e conteúdos e, por isso, não possuem uma visão unívoca e nem "um domínio unificado", nas palavras de Weeks (2001, p. 54). Podem variar ao longo da história, de uma cultura para outra ou entre diferentes grupos de uma mesma sociedade, e também ao longo de um desenvolvimento vital, caso seja considerada a biografia, a trajetória sexual e o contexto em que um sujeito está inserido.

Se contemplarmos minuciosamente a história, veremos que a sexualidade sempre foi assentada em discurso como alvo de contínua inquietação. Em seu livro "História da sexualidade", Foucault (1977) já alegava que desde o século XVIII o sexo tem aguçado um tipo de erotismo discursivo generalizado. Com o surgimento da AIDS e com os alarmantes índices de gravidez na adolescência, na década de 1980, as políticas públicas começaram a se movimentar em torno de programas de prevenção, na expectativa de amenizar tais problemas. Todavia, no contexto escolar, é possível notar alguns esforços no que tange à discussão da sexualidade, mas muitas vezes este assunto é tratado apenas sob o viés da prevenção, do medo da doença e da morte, adicionado a uma certa apreensão moral. A visão é quase sempre biológica (ensina-se a anatomia dos órgãos sexuais, como se configura a fecundação, o nascimento, os métodos contraceptivos, bem como as táticas de prevenção das doenças sexualmente transmissíveis). Outros fatores que favorecem esta discussão são as ideias que fazem menção à relação entre corpo e sexualidade 
apresentadas por Weeks (2001, p. 38):

embora o corpo biológico seja o local da sexualidade, estabelecendo os limites daquilo que é sexualmente possível, a sexualidade é mais do que simplesmente o corpo [...] A sexualidade tem tanto a ver com nossas crenças, ideologias e imaginações quanto com nosso corpo físico.

O pesquisador traduz tendo como base o pressuposto de que "os corpos não têm nenhum sentido intrínseco e que a melhor maneira de compreender a sexualidade é como um construto histórico" (WEEKS, 2001, p. 39). Sexualidade, então, não se restringe ao aspecto genital e à reprodução, envolve a dimensão do prazer, da subjetividade e da intersubjetividade. Está inserida no social e na cultura, da qual a dimensão de gênero deve ser levada em consideração. Por isso, ao se debater com meticulosidade o conceito de gênero, chegar-se-á a pesquisadores das Ciências Sociais como Scott, e dos teóricos pósestruturalistas. O vocábulo "gênero" começou a ser registrado e disseminado no movimento feminista da década de 1970. "As feministas começam a utilizar a palavra 'gênero' mais seriamente, num sentido mais literal, como uma maneira de se referir à organização social da relação entre os sexos" (SCOTT, 1990, p. 5). As mulheres proporcionaram notoriedade a esse conceito que é resultado de movimentos da emancipação feminina, contra a opressão. E é nessa conjuntura que, por exemplo, a discussão do conceito de gênero surge com mais intensidade.

As abordagens feministas pós-estruturalistas se arredam daquelas concepções que interpretam o corpo como uma instituição biológica universal para investigá-lo como um constructo sociocultural e linguístico, fruto e efeito das relações de poder. Nesse aspecto, o conceito de gênero passa a incorporar os matizes de construção social, cultural e linguística encalacradas com os processos que distinguem mulheres de homens, ao incluir aquelas tecnologias que determinam seus corpos, diferenciando-os e apartando-os como corpos dotados de sexo, gênero e sexualidade. O conceito de gênero prioriza, justamente, a análise dos processos de constituição dessas distinções - biológicas, comportamentais ou psíquicas - instituídas entre homens e mulheres; por isso, ele nos desvia de abordagens que propendem apenas à focalização de papeis e funções de mulheres e homens para aproximar-se de tratamentos muito mais amplos, levando a acreditar que as próprias instituições, os símbolos, as regras, os saberes, as leis, os comportamentos e políticas de uma sociedade são instauradas e perpassadas por representações e desígnios de feminino e de masculino e, concomitantemente, constroem e/ou ressignificam essas representações (ANDRADE, 2015; MEYER, 2003; BUTLER, 2003; LOURO, 2010; SCOTT, 1990).

A sexualidade é construída por cada um de nós, constitutiva da nossa subjetividade, propõe falar sobre nós mesmos e sobre nossos corpos, mas também é aquela que diz sobre a nossa cultura e sobre o contexto social em que estamos inseridos. Por isso Weeks (2010, p. 10) postula que este conceito seja tratado de forma singular e, quando generalizado, atentarmos para a expressão sexualidades, na medida em que se refere a um conceito profundamente problemático que não disponibiliza respostas fáceis para os desafios que aponta.

A expressão diversidade implica na condição de ser diverso, diferente ou mesmo não semelhante 
e, por isso, pode ser compreendida como opcional a esses termos. A diversidade sexual, segundo Weeks (2011) é a área mais contestada e controversa por causa das origens da concepção. Também se relaciona com sentidos de multiplicidade e singularidade, na medida em que apresenta a ideia que todos e todas inserimo-nos em categorias de gênero e sexualidades inerentes e constituintes de ser humano. No uso cotidiano essa expressão apresenta-se como uma forma de nomear aqueles que não são heterossexuais. Isto significa que a heterossexualidade também está incluída na diversidade sexual, como uma dentre outras formas de se viver a sexualidade.

Assim, falar de diversidade sexual implica levar em conta as múltiplas faces assumidas pela esfera sexual humana considerando as diferenças culturais, os distintos hábitos e expressões, as experiências e aspirações de vida, os costumes e comportamentos, as emoções e identidades, o modo de agir e a forma como nos vemos e como somos vistos pelos outros na complexidade das interações sociais. Dessa forma, a diversidade sexual engloba uma multiplicidade de práxis, comportamentos e atuações que divergem dos moldes e padrões convencionais, adotados pelos heterossexuais, completamente aceitos e assimilados pela nossa sociedade.

\section{Escola, normas e diferenças}

Falar de escola implica reconhecermos que, cotidianamente nas instâncias pedagógicas, as relações entre sujeitos e grupos vivenciam conflitos, disputas e jogos de poder em função de embates culturais que ocorrem devido às diferentes, distintas e desiguais formas como os sujeitos se constituem antes mesmo de entrarem no processo escolar. Por outro lado, a escola também é constituída por sujeitos com culturas muito próprias e que criam também no âmbito escolar culturas institucionais partindo de suas próprias concepções pessoais. Isso significa que a escola também é produtora de desigualdades, diferenças e distinções (Louro, 2008b) na medida em que divide os que a integram por múltiplos mecanismos de classificação, ordenamento e hierarquização por meio dos espaços, currículos, docentes, discentes, regulamentos, avaliações que, de forma explícita ou implícita produzem as diferenças entre os sujeitos.

Desde muito cedo os sujeitos aprendem o que pode/não pode fazer, na medida em que a escola informa o lugar de pequenos/grandes, de meninos/meninas, informa suas marcas, seus símbolos e arranjos arquitetônicos que vão delineando os sentidos, os movimentos, as falas, os sons, os ritmos, os silêncios e as múltiplas formas de organização e do fazer institucional cotidiano. Esses indícios são apropriados pelos sujeitos de forma própria e individual e configuram-se como diretrizes pessoais para um ser/estar na escola. Dessa forma, essas construções subjetivas mostram-se como aprendizados que colocam “cada um no seu lugar". Mas, qual é o lugar de cada um? Como esse lugar se delineia?

Um aprendizado eficaz, continuado e sutil vai mostrando para cada sujeito qual é o seu lugar em 
função do seu ritmo, de sua disposição física, de sua postura, de seus comportamentos, de suas interações que são incorporados por meninos e meninas envolvidos em tais dispositivos e práticas que constroem suas identidades escolarizadas (LOURO, 2008b). Assim, crianças, jovens e adultos constroem suas próprias experiências que atravessam, confirmam e até produzem as diferenças.

$\mathrm{Na}$ escola as normas estão em todas as partes, não emanam de um só lugar, são expressas por observações cotidianas e por recomendações que perpassam por todos e todas, servem como referências e, dessa forma, naturalizam-se, tornam-se normais. Desse modo, tudo que não se enquadra nesse padrão da normalidade, fica marcado porque difere, pela sua diferença. Podemos, então, pensar que a diferença não é natural, todavia torna-se naturalizada na medida em que é produzida por processos discursivos e culturais, portanto, a diferença é ensinada na escola por meio de políticas e de saberes legitimados e reiterados por variadas práticas e pedagogias culturais. Inferimos que essa seria uma maneira de explicar o que os jovens quiseram dizer com "aquilo" - com o que não sei dizer o que é porque é diferente.

Com isso, viver as diferentes sexualidades na escola implica reconhecer as múltiplas formas de experimentar prazeres e desejos, de dar e receber afetos, de amar e ser amado que são ensaiadas e ensinadas nas culturas (Louro, 2008). Essa variedade assusta, desestabiliza, foge de controles e de normas, por isso descontroem certezas, verdades e padrões.

\section{“Não sei o que fazer com aquilo": LGBTfobia e Educação}

Mais do que uma conversa entre a constituição de gênero e a sexualidade, o que parece suceder é mesmo alguma "confusão" entre esses dois termos. Inclusive parece plausível dizer que entre eles o que se exprime como uma dificuldade para a escola são aquelas tangenciadas à sexualidade, sobretudo, às dissidências sexuais ${ }^{3}$. A diversidade sexual faz parte do cenário escolar cotidianamente (FERRARI, 2000), seja como caso (estudantes categorizados como tal) ou como tema (quando o assunto surge nas interações entre os atores escolares). Mediante essa circunstância, cabe nos indagar: de que maneira a diversidade sexual é evidenciada no discurso escolar? As que estão prestando esses discursos? A quem está apoiando e a quem está molestando? Até que limite a escola está debatendo o que surge?

A instituição escolar está sendo convidada a mirar para a arena de combate a que se encontra as dissidências sexuais, principalmente no que tange à luta contra a LGBTfobia. Os movimentos gays, lésbicos e transexuais, preocupados com o desarranjo dos determinantes das sexualidades nãoheterossexuais, geralmente atrelados à ideia de patologia e pecado, e na edificação de conceitos e discursos mais positivos dessas identidades, cooperaram para alocar a educação no núcleo das atenções, ao exigirem investimentos e uma parceria mais efetiva com o Estado, construindo material educativo e preocupando-

\footnotetext{
${ }^{3}$ Trata-se das sexualidades não-hegemônicas, que escapam do engessamento imposto pela heteronormatividade.
} 
se com o desenvolvimento e conhecimento de professores/as.

O termo LGBTfobia é usualmente empregado em menção a uma coletânea de sentimentos negativos (tais como abjeção, repulsa, animosidade, suspeita, ojeriza ou receio), que costuma provocar ou atrelar-se a intolerâncias e processos de exclusão e violência contra sujeitos homossexuais, bissexuais e transgêneros (travestis, crossdresseres e transexuais) e, de forma mais genérica, contra sujeitos cujas marcas de gênero não se coadunam com os arquétipos hierárquicos de masculinidade e feminilidade, tal como aconteceu na experiência aqui retratada. A LGBTfobia opera para além da agressividade e da marginalização contra LGBT: ela se une a concepções e arcabouços hierarquizantes sexistas, que enxerga somente a heterossexualidade como norma. A condição heterossexual é fixada como exclusiva possibilidade legal de vivência, e as dissidências sexuais são entendidas como subversivas, bizarras, ilícitas, patológicas e/ou pecado.

Para Borrillo (2010, p. 13), o conceito de homofobia é a conduta agressiva cujo alvo são os/as homossexuais, homens ou mulheres, e se baseia na designação do outro como inferior, avesso ou anômalo, de modo que sua diferença o desloca para fora da natureza comum dos humanos. O liame dos afixos "fobia" e "homo" tem sido questionado por intelectuais, pesquisadores e militantes por sugerir a impressão de que se trata de um dilema pessoal e psicológico do âmbito das neuroses particulares e das muitas fobias existentes. Essa acepção de fobia poderia ocasionar uma determinação de terapia individual para sujeitos homofóbicos, no campo da psiquiatria ou da psicologia.

No entanto, as pesquisas brasileiras mostram a expansão desse grave problema. O estado de marginalização e rejeição a que são relegados os sujeitos que não compactuam com o preceito heterossexual é bem mais difundido do que se possa supor. No país, a violência por intolerância sexual extermina cerca de 150 pessoas por ano. De acordo com Junqueira (2009), o Brasil é o campeão mundial de homicídios contra os sujeitos cuja orientação sexual difere da sexualidade legitimada socialmente, uma vez que a estatística brasileira gira em torno de uma morte a cada três dias. Aliás, é importante admitir e estar cauteloso frente aos aspectos culturais e regionais que geram matizes distintas em relação ao nível de abjeção desses indivíduos.

De maneira tênue, a LGBTfobia permeia o cotidiano da população. Ela é acatada e doutrinada nas instituições escolares. Atravessa as acepções curriculares e as diretrizes pedagógicas. Mesmo com a aparente melhoria capitaneada pelo PNLD (Programa Nacional do Livro Didático), a LGBTfobia ainda se faz presente nos livros didáticos. Além disso, corporifica-se no momento da chamada, quando, por exemplo, o nome social de travestis e transexuais não é considerado; nas brincadeiras e nas piadas (superficialmente "inocentes" e até utilizadas como recurso didático) e na objetificação do sujeito, na tentativa de "tirá-lo" da esfera humana. Quando os/as estudantes me perguntaram o que fazer com "aquilo", esta palavra não foi utilizada aleatoriamente. Ela desmerece, inferioriza e retira da pessoa qualquer indício de humanidade: é um corpo abjeto.

A LGBTfobia é uma ferida social que deixa o segmento LGBT assaz vulnerável. De acordo com 
a plataforma virtual do Programa Nacional de DST e AIDS: "A maior parte dos gays foi morta dentro de suas próprias casas, enquanto a maioria das travestis perdeu a vida nas ruas. Segundo os dados do Grupo Gay da Bahia, menos de 10\% dos assassinos de homossexuais são presos”. A baixa estatística de soluções para esses tristes episódios pode ser um sinal de que esse tipo de homicídio é considerado como prática razoavelmente admissível, uma vez que se refere a indivíduos vistos, pelo senso comum, como pertencentes à condição marginal da sociedade; à margem também de suas normas e moralidade. Inclusive, a disparidade social e os aspectos socioeconômicos têm influência relevante na configuração desta problemática.

A experiência circular dessas violências por sujeitos LGBT pode ocasionar a LGBTfobia internalizada, que é a internalização de status negativos quanto a sua própria identidade sexual (Moita, 2003). É uma construção derivada dos discursos que são engendrados e ventilados pelas instituições socializadoras e que reforçam o raciocínio binário, sexista e a heteronormatividade compulsória (LOURO, 2010, 2001; FOUCAULT, 1977). Por isso, pode-se afirmar que a LGBTfobia está intrinsecamente imbricada à heteronormatividade, ou seja, à ideia de que a heterossexualidade é a norma, “isto é, a obsessão com a sexualidade normalizante, através de discursos que descrevem a situação homossexual como desviante” (BRITZMAN, 1996, p. 79). Diante dessa concepção que é imposta à sociedade e que também perpassa o cotidiano das escolas, ao incidir nos confrontos e nas negociações identitárias, a LGBTfobia passa a ser compreendida como a "discriminação contra as pessoas que mostram, ou a quem se atribui algumas qualidades (ou defeitos) atribuídas ao outro gênero. A homofobia engessa as fronteiras do gênero". (WELZER-LANG, 2001, p. 465).

Com base nessas concepções, parece plausível intuir que o que está em jogo em sala de aula quando a suposta homossexualidade serve de pretexto para degradar, hostilizar e violentar os sujeitos que fogem do arquétipo hegemônico do masculino e do feminino são os predicados do que é ser homem e do que é ser mulher na sociedade brasileira. Sendo assim, surgem falas como "não sei o que fazer com aquilo".

Enfim, a LGBTfobia é um problema que aumenta cotidianamente, e os resultados de tais atos são refletidos também na universidade, onde sujeitos de sexualidades dissidentes padecem com chacotas, risos e piadas de cunho discriminatório. A instituição escolar, como espaço de formação, local onde se constroem cidadãos e se engendram identidades, deve admitir a presença de tais questões em suas salas de aula e perceber a necessidade imediata do questionamento e reconhecimento da diversidade sexual existente, ao sobrepujar a intolerância e a violência conferidas aos sujeitos homossexuais e transexuais (JUNQUEIRA, 2009). 


\section{Articulações reflexivas}

Percebemos que, ainda hoje, as questões de gênero e sexualidades continuam atreladas às ideias de riscos, de ameaças, de juízos de valor e deixam de ser pensadas e vividas em relação ao prazer, às realizações e ao desejo de ser feliz.

Nossas questões, como professores formadores e professoras formadoras de futuros docentes, circulam pela responsabilidade sobre os significados de concepções e de expressões que comumente utilizamos nas relações com nossos alunos e alunas acerca do que é normal/anormal, natural/não natural e de tantos outros binarismos que ainda conformam nossa cultura brasileira.

Precisamos assumir nosso compromisso de desconstruir e desnaturalizar processos de normalização e padronização das sexualidades e gêneros presentes nas escolas. Até que ponto acreditamos que estamos protegendo nossas crianças e jovens nas suas purezas e nas suas verdades das “contaminações" do diferente, do estranho, do excêntrico? Seria a invisibilidade uma estratégia para que o diferente/estranho/excêntrico permaneça no convívio escolar? Todavia, a visibilidade do diferente/estranho/excêntrico não seria uma forma de excluí-lo?

Instalar as possibilidades para a legitimação da diversidade sexual na educação requer uma visão coletiva e um painel de referências nutrido pelo diálogo, por preceitos de justiça e equidade, por valores democráticos e pelo entendimento do papel da diversidade e da pluralidade cultural na dinâmica educacional. Nesse aspecto, acredita-se cabível não somente impedir, mas desmantelar atitudes demarcadas por desígnios inatistas, essencializantes ou naturalizantes, bem como posições incentivadas por premissas reacionárias, regressivas ou separatistas.

Trata-se de promover um processo de ressignificação simbólica e política que, como tudo o que diz respeito à democratização das interações e à institucionalização de novas práxis pedagógicas, é ininterrupto, incompleto, sempre passível de ser repensado, expandido e aprimorado. E por também estar vulnerável a intimidações e a anacronismos, esse processo demanda sempre maior comprometimento, dinamicidade, responsabilidade e iconoclastia, em múltiplos contextos, graus e concepções.

Se as identidades de gênero, as sexualidades, os corpos, os sujeitos, as representações, os paradigmas culturais, as regras, os princípios, as relações humanas, as formatações políticas e a pedagogia não compõem realidades inalteráveis, mas, sim, organismos dinâmicos, em sucessiva modificação, existem lacunas para o questionamento, a reflexão e a ressignificação constante do trabalho dos sujeitos e da sociedade sobre si mesmos. Este é um dos encargos de quem atua na educação e gera reflexões, saberes e ressignifica representações.

Sabemos e reiteramos nosso compromisso como docentes e atores sociais que vivemos cotidianamente processos que envolvem não apenas construção de conhecimentos, mas também processos sensíveis para desengessar ou mesmo desestabilizar padrões normalizadores no campo das 
"políticas de verdades" que funcionam como forças em campos problemáticos como o de gênero e das sexualidades na instituição escolar.

Aprendemos com Michel Foucault (1977) que verdades são fabricações sociais baseadas em condicionantes históricos e exercem sobre sujeitos poderes que as regulam, classificam, hierarquizam e dirigem suas ações. Nesse sentido, verdades não decorrem de raciocínios lógicos e científicos, todavia configuram-se como saberes fabricados sobre o Outro na busca por explicar condutas, prescrever medidas, orientar ações, determinar procedimentos reabilitadores, corretivos e, até mesmo, reorganizar comportamentos e produzir discursos morais fundamentados por boas intenções de racionalidade.

Dessa forma, cabe a nós professores e professoras estarmos atentos para levar nossos alunos e alunas a vivenciar experiências como exercícios e desafios para costurar ideias e produzir novas formas de escuta de si e do Outro, de modo que as diferenças não sejam negadas ou mesmo tomadas como objetos de ameaça, de ódio/repulsa, mas como inquietações com possibilidades de pensar novas formas, igualmente legítimas, de existir, de conviver e de respeitar.

\section{Referências}

ANDRADE, L. N. Travestis na escola: assujeitamento e resistência à ordem normativa. Rio de Janeiro: Metanoia, 2015.

BENJAMIN, Walter. Obras escolhidas. Charles Baudeleire um lírico no auge do capitalismo. 1 ed. V. 3. Tradução de José Martins Barbosa, Hemerson Alves Baptista. São Paulo: Brasiliense, 1989.

Brasiliense, 1993.

Magia e Técnica, Arte e Política. Tradução de Sergio Paulo Rouanet. 5. ed. São Paulo:

BORRILLO, Daniel. Homofobia: história e crítica de um preconceito. Belo Horizonte: Autêntica, 2010.

BRITZMAN, Deborah P. "O que é essa coisa chamada amor: identidade homossexual, educação e currículo”. Revista Educação e Realidade, v. 21, jan./jun. 1996, p. 71-96.

BUTLER, Judith. Problemas de gênero: feminismo e subversão da identidade. Rio de Janeiro: Civilização Brasileira, 2003.

CONNELL, Robert W. Políticas da masculinidade. Revista Educaşão \& Realidade, Porto Alegre: UFRGS, v. 20, n.5, jul/dez, 1995. p. 185-206. 
FERRARI, Anderson. O professor frente ao homoerotismo masculino no contexto escolar. Juiz de Fora: Dissertação de Mestrado em Educação, PPGE/UFJF, 2000.

FOUCAULT, Michel. História da sexualidade, v 1. A vontade de saber. Tradução de Maria Theresa da Costa Albuquerque; J. A. Guilhon de Albuquerque. Rio de Janeiro: Graal, 1977.

JUNQUEIRA, Rogério D. Educação e Homofobia: o reconhecimento da diversidade sexual para além do multiculturalismo liberal. In JUNQUEIRA, Rogério D. (org.). Diversidade Sexual na Educação: problematizações sobre a homofobia nas escolas. Brasília: MEC/Unesco, 2009, 367-444.

LOURO, Guacira Lopes. Pedagogias da sexualidade. In: LOURO, Guacira Lopes. (org.). O corpo educado: pedagogias da sexualidade. Belo Horizonte: Autêntica, 2001. p. 07-34.

. Currículo, gênero e sexualidade: o normal, o diferente e o excêntrico. In: LOURO, Guacira Lopes. FELIPE, Jane. GOELLNER, Silvana Vilodre (orgs) Corpo, gênero e sexualidade. Um debate contemporâneo na educação. $5^{\mathrm{a}}$ ed. Petrópolis, RJ: Vozes, 2010.

. Gênero e sexualidade: pedagogias contemporâneas. Revista Pro-Posições, vol. 19, nº 2 (56) maio/ago, 2008a. p. 17-23.

Gênero e sexualidade e educação. Uma perspectiva pós-estruturalista. $10^{\mathrm{a}}$ ed. Petrópolis, RJ: Vozes, 2008b.

LOURO, G. L. Gênero, sexualidade e educação: uma perspectiva pós-estruturalista. 2. ed. Petrópolis: Vozes, 1998.

MEYER, D. E. Gênero e educação: teoria e prática. In: LOURO, G. L.; NECKEL, J. F.; GOELLNER, S. V. (Org.). Corpo, gênero e sexualidade: um debate contemporâneo na educação. Petrópolis: Vozes, 2003.

SCOTT, J. Gênero: uma categoria útil de análise histórica. Educação \& Realidade, Porto Alegre, v. 15, n. 2, p. 5-72, jul./dez. 1990. Número especial Mulher e Educação.

WEEKS, Jeffrey. O corpo e a sexualidade. In: LOURO, Guacira Lopes (org.). O corpo educado: pedagogias da sexualidade. Tradução dos artigos: Tomaz Tadeu da Silva. 2. ed., Belo Horizonte: Autêntica, 2001. p.35-82.

. Sexuality. Third edition. London: Routledge. 2010.

. The languages of sexualitiy. London: Routledge. 2011.

WELZER- LANG, D. A construção do masculino: dominação das mulheres e homofobia. In Revista de Estudos Feministas, vol.9 n. 2. Florianópolis. 2001, pp. 460-472. 